\title{
BASIC PRINCIPLES AND METHODS OF DENDROCHRONOLOGICAL SPECIMEN CURATION
}

\author{
PEARCE PAUL CREASMAN* \\ Laboratory of Tree-Ring Research, University of Arizona, Tucson, AZ, 85721-0058, USA
}

\begin{abstract}
Dendrochronological collections include continuously expanding multi-taxon records of tree growth that encompass millennia and often offer irreplaceable sources of biological, environmental, and cultural information. Nevertheless, each departure of a scholar from the field - whether because of death, retirement, career change, shift in research priorities, or even move to a new institution - places collections in increased danger of being lost as viable resources. Without an organized and concerted effort to address outstanding and future issues of specimen curation, dendrochronology as a whole may become mired in the same trap that befalls many other scientific fields: collections apathy. Dendrochronological collections exist as a result of decades of effort and should function to support current and future scientific endeavors, education, and outreach, but cannot do so without adequate attention to their future. Intended as a "call to arms" this paper, focused on dendrochronology in the academic and public sector, aims to encourage discussion and, more importantly, to provide a foundation for and to instill a sense of urgency regarding long-term preservation of dendrochronological specimens.
\end{abstract}

Keywords: Dendrochronology, collections, archives, curation, curate, standards, procedures, samples.

\section{INTRODUCTION}

"... the future of dendrochronology is not just about what will be done in research terms in the field... it must also address the legacy of previous work." (Baillie 2002:70)

A significant part of the legacy of dendrochronology has been and will be its superlative collections. The nature of dendrochronology, especially chronology-building, often calls for the collection of a large volume or quantity of specimens and their long-term curation (Stokes and Smiley 1968; Baillie 1982). Because long chronologies are the "backbone of all tree-ring research" (Kuniholm 2001:38) and an "ample supply" of wood is one of Bannister's prerequisites for successful dendrochronology (1963:164), it is no surprise that many large and diverse collections have been built worldwide over the past century, particularly since the 1960s (Dean 2009; Eckstein and Cherubini 2011). Despite increasing recogni-

\footnotetext{
*Corresponding author: pcreasman@1trr.arizona.edu
}

tion and demand for dendrochronological research worldwide, a vast quantity of existing primary materials (i.e. the wood) remains both inaccessible to the research community and at risk of being lost, a fate likewise faced by a variety of specimens collected for other disciplines. For general scientific examples see Mares (2009).

Responsible researchers consider the future of their materials beyond their initial applications. Collecting and processing of specimens can be costly in time and funds. Yet, too few researchers possess the sense of urgency that leads to the development or execution of procedures that can support future use of the specimens and thus the maximization of resources. Some scholars learn of curation needs only after experiencing, narrowly avoiding, or succumbing to an emergency.

This issue is not unique to dendrochronology. In many other scientific fields, inadequate space and staffing have created an extensive backlog in the modernization of collections (Flattau et al. 2008; Skog et al. 2009). In many ways dendrochronology is ahead of related fields in addressing 
specimen care. The field has recognized the fundamental issues and is actively working towards a resolution, as evidenced by the presence of data repositories (ITRDB [www.ncdc.noaa. gov/paleo/treering.html], Database of European Chronologies [www.dendro.bf.uni-lj.si/first.html], IMPD [www.ncdc.noaa.gov/paleo/impd/paleofire. html], the WSL's Xylem Database [www.wsl.ch/ dendro/xylemdb/], LUSTIA [http://lustiag.pp.fi/], etc.) and working groups dedicated to standardizing data and metadata collection, notably the Digital Collaboratory for Cultural Dendrochronology (Jansma et al. 2010; www.dendrochronology. $\mathrm{eu} /$ ). Additional evidence can be found simply in the existence of substantial dendrochronological collections around the world, some of which have been maintained for a century, and their continued application in reams of academic manuscripts of the highest caliber.

Yet, there are broad disparities in the significance placed on dendrochronology and its specimens by national research agencies and agendas. For example, the Dutch National Research Agenda for Archaeology has specifically included dendrochronology in its scope (Jansma 2006; www.noaa.nl). Although English Heritage has outlined techniques for collection, preparation and analysis of dendrochronological specimens (i.e. Laxton et al. 2001; Jones 2010), it has not defined standards for storage and safekeeping, which is left to individual laboratories (Hillam 1998). Consistency is also lacking in the United States: in the guide to the responsible conduct in scientific research authored by the National Academy of Sciences et al. (2009), specimens are critically overlooked, whereas the National Science and Technology Council (2009) paid specific attention to this issue in a report entitled "Scientific Collections: Mission-Critical Infrastructure for Federal Science Agencies". The broader points and lessons of the latter work can be applied directly to dendrochronological collections.

Given all of the above, this paper is not and should not be construed as an indictment of past practices within this field, but as a call to arms. Data and metadata are important, but care of the source material itself must not go overlooked.
Again, like many fields, dendrochronology lacks a tailored curation guide that can be used to train new researchers, inform granting agencies, and serve as a reference for established institutions and scholars. Stokes and Smiley (1968) provided an enduring introduction to specimen collection, processing, and analysis, but a curation supplement is needed because scientific responsibility does not terminate with analysis or publication.

Curation concerns have been noted not infrequently for at least a decade in the dendrochronological literature and were identified at least as early as the 1960s when Stokes and Smiley (1968) compiled their classic text. It seems that the topic has also been broached informally at international conferences with regularity, possibly at the "First Tree-Ring Conference" in 1934 (see Glock 1934; Nash 1999). To the best of the author's knowledge, the only published effort to detail specific standards of care for dendrochronology specimens comes from government policies guiding the collection of tree-ring specimens from Tasmanian public reserves (Harris et al. 2009). As is often the case with trailblazers, Harris et al. clearly state the problems, but leave much room for consideration ("Protocols outlining standard storage techniques are not considered in detail in this paper..." 2009:150). The paper presented here offers a continuation of such efforts, which, it is hoped, will eventually result in a guide, or at least guiding principles, for the care of dendrochronology collections. Any such guide/protocols should make use of the many years of practical experience, trial, and error from all stakeholders in the field (the public and private spheres) and it is further hoped that readers of this paper will actively contribute from their own experience to improve on these suggestions.

Although this paper provides a set of recommendations, which, ideally, would be applied indiscriminately across all sectors of the field, the author recognizes that in some regions (i.e. Europe, in part as the result of the Valetta Convention) a division exists between academic or public sector and commercial or private sector work. A subsequent manuscript will be forthcoming to further discuss how the private sector might practically implement the recommendations below 
without deviating from the highest standard of care.

\section{RATIONALE: WHY CURATE DENDROCHRONOLOGICAL SPECIMENS?}

The potential exists for much greater use of the dendrochronological collections worldwide, but this expansion depends, in part, upon proper housing and management of specimens, and improved knowledge of and access to collections. Safe, organized, and readily accessible specimens will encourage greater use of the materials by scholars, as well as for public outreach. Furthermore, ongoing loss of tree-ring resources because of environmental and social changes (e.g. tree mortality, forest harvesting, fire, hydroelectric damming, human intervention and population growth) means that existing tree-ring collections will be increasingly valuable in coming decades and centuries for study by archaeologists, biologists, chemists, and a variety of earth scientists (see U.S. National Science and Technology Council et al. 2009:16-17).

Over the past half century dendrochronology has embraced the use of various new tools and techniques, including isotopic and chemical analyses, and various methods of measuring wood density and micro-anatomy (e.g. Dean et al. 1996; Solomina and Cherubini 2002 and the entire volume of Dendrochronologia 20 1/2; the TRACE conference proceedings [http://www.tree-ring.org/ content/trace]). There is every reason to suspect that this trend will continue (e.g. Čufar 2007; Eckstein and Schweingruber 2009; McParland et al. 2009; Creasman 2010; Santiago-Blay et al. 2011). Moreover, it is extremely valuable in the context of regional to global-scale studies to unify and combine data from many collections distributed across broad spatial and temporal scales (e.g. Cook et al. 2004).

Re-analyses of existing tree-ring collections and data with new tools, techniques, or in light of subsequent discoveries has proven exceptionally productive (e.g. Schultze et al. 2004). A prime example is the Laboratory of Tree-Ring Research's (LTRR) archaeological Synthesis Project (1963-1975), which resulted in the publication of a critically important series of reports and enabled much subsequent research (Nash 2000). The adjustment for cockchafer beetle outbreaks (Melolontha melolontha L. and M. hippocastani F.) in the Hohenheim University oak and pine tree-ring chronology spanning the past 12,500 years, which serves as the standard for calibration of the radiocarbon time scale in central Europe (Friedrich et al. 2004), is another critical example. The outbreaks were verified by specific anatomical features in the wood (Friedrich et al. 2004:1114). The above examples clearly demonstrate the profound impact that dendrochronological collections can have on archaeology and earth sciences.

Collecting and preparing a usable tree-ring specimen commonly requires a considerable initial investment of time and funds. Even after such initial investment is made, the physical specimens often remain largely inaccessible beyond their host institution/repository, limiting their value. Indeed, some tree-ring collections have been destroyed, in part or in full, following their initial use, because of a shortage of storage capacity, limited personnel resources, inadequate preservation technology, or lack of vision regarding potential future uses (e.g. Baillie 2002; Dean 2006).

The Hawley/Bell Collection, currently housed at the University of Arizona, is an example of some risks to which specimens are exposed in the absence of a specific long-term plan for curation. Thousands of archaeological and living-tree specimens from the U.S. Midwest were collected by Florence Hawley in the 1930s and 1940s (e.g. Hawley 1941; Nash 1999). Until the late 1940s, the specimens were in the care of the University of Chicago and its dendrochronology program. When Hawley accepted a position at the University of New Mexico in the late 1930s, it seems she neither brought the specimens with her nor made long-term arrangements for their preservation. Approximately 10 years later, the University of Chicago shuttered its dendrochronology program and was "on the verge of discarding all of the treering samples it had accumulated over the years" (Dean 2006:33). Fortunately, Robert E. Bell, a Midwestern archaeologist trained in dendrochronology by Hawley, recognized the value of the 
specimens and was able to rescue a substantial, yet incomplete, portion of the collection. Despite Bell's employment by the University of Oklahoma for 33 years, and Hawley's employment at the University of New Mexico for 37 years, it seems that the burden of care fell solely and personally on Bell until the University of Arizona accessioned the combined collection in the 1970s (Dean 2006). Such consolidation has not been uncommon in dendrochronology (Robinson et al. 1992). Some of the most common anecdotes of specimen and metadata loss are reported when an individual or research program changes institutions (as above), but this is the precise opportunity to negotiate for permanent care: when the individual has leverage.

Currently, the Hawley/Bell Collection requires approximately 8.8 cubic meters (311 cubic feet) of storage space. Although most of the metadata associated with the specimens can be accounted for, the records are in need of much attention to associate each specimen, digitize data and metadata, and otherwise make the collection practically useful for those presently unfamiliar with it. Despite limited use to date, the material must be maintained; re-collection is impossible because much originated from archaeological sites and forests long since cleared. The surviving portion has relied on altruistic individuals and academic charity to prevent its loss. Under the current and foreseeable economic conditions in academe, at least in the United States, such commitments are not likely to be repeated, at least not on the previous scale.

Whispers from virtually all regions of the world where dendrochronology has been attempted recall similar situations as above. For example, it is likely that thousands of unique wet paleoecological and archaeological specimens spanning from 8,000 BC to present are lying on shelves throughout Europe without proper attention to their specific conservation needs or future utility (E. Jansma, personal communication, 22 March 2011; C. Bjordal, personal communication, 25 May 2011).

Perpetual institutional curation commitments are and will be critical to the future of dendrochronological specimens. Yet, even with such agreements in place, after the primary researchers are gone or a discipline falls out of favor, institutions can unilaterally revise such agreements. Therefore, the safest way to ensure preservation of specimens seems to be to build endowments exclusively for this purpose. The suggestion that such resources could be secured through estate planning (P.I. Kuniholm, ITRDB forum, 6 May 2010, http://listserv.arizona.edu/) would seem a viable method to ensure that the fruits of a career do not soon fuel a bonfire.

\section{GUIDING PRINCIPLES FOR SPECIMEN CURATION}

\section{Preservation}

(1) Long-term preservation and continued access to wood specimens and associated data/metadata are crucial to the field. Specimens must be continuously and readily available as vouchers for past research and for new observations and different types of analyses, including with new technologies.

(2) Preservation is critical, as many specimens cannot be collected again. Often the material no longer exists in nature (Arnott 2008), and archaeological excavation destroys a site, making it imperative to preserve specimens for as long as possible and at the highest standard.

(3) Specimens without associated metadata, or with incomplete metadata, are extremely limited for future use. Metadata (on paper and in digital formats) must be preserved and maintained in association with the specimen(s).

(4) Specimens and analogous metadata should be stored in secure, humidity and temperaturecontrolled spaces that ensure protection from flood, fire, and degradation, including infestation, but allow accessibility for scholarly research.

(5) Digital data and metadata should be backed up in multiple locations and files should regularly be converted to contemporary formats. See DANS (www.datasealofapproval.org) and Archaeology Data Service/Digital Antiquity (http://guides. archaeologydataservice.ac.uk/).

(6) Portions of dendrochronological collections remain the property of various governments or government entities and should be afforded a high 
standard of care to maintain the public trust and goodwill for the discipline. However, any entities claiming ownership should also provide financial or in-kind support for the care of the material (permittees should include stipulations for future care in the collection agreements/contracts).

(7) Regardless of ethical, scientific, and financial impetuses to curate, many specimens fall under a variety of legal requirements for curation. Nations, states, and municipalities can each have their own requirements (e.g. Harris et al. 2009). As a precaution, all specimens (natural history and archaeological) should be subjected to the highest standard of care.

\section{Curation}

(1) Dendrochronology involves many fields of research and each project may have different analytical requirements reflected in specimen preparation and long-term curation needs. Specimens should be curated in order to preserve their viability for the original research intent (Stokes and Smiley 1968). For example, chronologybuilders may glue a core to a manufactured wooden base for ease of use, which may result in the specimen being unsuitable for other applications, such as chemical analysis.

(2) It is the responsibility of the principal investigator to appropriately request funds, budget for and ensure the long-term care, cataloguing, and proper storage of the specimens they collect, including data and metadata. This should include plans for specimen care at the end of the investigator's career and at the end of each project. Contra Baillie (2002:70), those who collect the material should be held responsible for its care. If those most interested in the material are not willing to claim this responsibility, who else can be expected to invest in its future?

(3) "Budgets for development projects or academic research are remiss unless there is a line item for curation. Without curation... collections are lost" (Stankowski 2009:6). Organizations that support dendrochronological fieldwork, such as national and local scientific funding and permitting agencies, should be encouraged to consider the future of the collections they have or will support, and require that appropriate arrangements for their care be made.

(4) Perhaps the most important component of the future of dendrochronological curation is education. Students of dendrochronology should be required to dedicate a portion of their training or coursework to learning the highest standard of care for the specimens with which they work (some programs already do this). Faculty advisors should enforce this requirement; the students will be the next generation of scholars and bring their training with them as habitual practice in the field.

\section{Access}

(1) Dendrochronology is predicated on the concept of comparing and combining observations and measurements of tree-ring specimens, often from many locations and time periods. This work requires access to the primary materials from which observations and measurements derive, as well as to ancillary materials and data associated with the specimens. The willingness to share and exchange data and information has been critical to the development of the field (Kuniholm 2002; Eckstein and Cherubini 2011) and should continue to extend to the specimens themselves.

(2) Specimens should be continuously and readily available as vouchers for past research and for new observations and different types of analyses, including with new technologies. Should questions ever arise about a given dataset, it is critical that the original material be available for reinterpretation and confirmation.

(3) When tree-ring specimens are cataloged only in paper files, their usefulness is limited, in some cases almost exclusively to those researchers able to travel to the collections. This "paper barrier" should be eliminated; however, this does not imply that records on paper should be discarded or discontinued.

(4) Each researcher or institution should provide access, via the Internet, to a searchable catalog of specimens and at least basic metadata (i.e. current specimen location, project, collection intent, species, geographic origin, time range represented, 
date collected, representative specimen image, and publication citations). Much can be gained by collaboration, but knowledge of available material is a critical step forward. Ideally, such a catalog would include an indication if the following are or can be made available and under what conditions: derived data, photographs and coordinates of the site, measurement files, final chronologies, etc. For discussions of data and metadata see Brewer et al. (2010) and especially Jansma et al. (2010).

(5) It is likely that requests for access to primary materials will increase as knowledge of collections expand. Institutions and individuals should provide physical access to specimens in their care for serious inquiries, provided that (a) access does not conflict with or impede current research goals of the host, (b) requests are within the limitations of available resources, (c) requests are made in accordance with the host institution's stated policies and procedures (e.g. http://www.ltrr. arizona.edu/collection/; such policies can also be informed by collection management practices in related fields such as ice core studies, found here: http://www.nicl-smo.sr.unh.edu/ and http://www. nicl-smo.sr.unh.edu/access/policy.html).

(6) Specimens should generally be considered community property, not institutional or personal property.

\section{WHAT SHOULD BE CURATED?}

As space, staff-time, and funds for infrastructure are typically in short supply, there are practical limits to what can or cannot and should or should not be curated. When national standards or research agendas are absent or silent on this matter, such decisions should be made on an institutional and per-project basis, assisted by institutional guidelines or discipline-wide standards. For example, some permitting agencies require that biological and agricultural specimens be returned, autoclaved, or incinerated on completion of research.

At a minimum, voucher specimens that can be used to retest or reanalyze previous results should be maintained. In the event that analysis consumes the specimen, it is especially important that all reasonable efforts be made to secure a duplicate specimen for archiving. These "backup" specimens could be a researcher's greatest allies in the event that their methods or results are questioned. Additionally, as is the nature of any science, methods improve and specimens can and should be re-analyzed. (See also U.S National Science and Technology Council 2009:18-20).

\section{HOW TO BUDGET FOR CURATION}

Appropriate curation costs will vary based on location, volume, intent, specimen size, and a host of other factors. As such, it is not possible to provide a single, reasonable figure for the curation of all specimens in all locations. A common method for estimating curation fees is through a flat rate per cubic or linear unit of storage necessary. Generally, the curation of archaeological materials is the best comparison (Childs and Kinsey 2003; Childs 2004). Lyons and Vokes (2010) provide a cautionary and frank discussion of maintaining an archaeological repository and its associated costs, which can be used as a guide.

Curation funds should be specifically requested in all grant proposals and contracts and reserved for this expressed purpose. Agencies or organizations that are willing to support specimen collection and analysis should be encouraged and requested to support the long-term care of those materials. Every future application or use of archived specimens compounds the return on the original funding investment.

Principal investigators and institutions should not classify curation expenses as "contingency" or "surplus" funds for the proposed research, or, worse, use them to cover unexpected expenses. Doing so may endanger the allocation of funds for curation requested in other proposals for everyone in the field.

\section{HOW TO CURATE SPECIMENS}

The information provided below was prepared specifically for the curation of dendrochronological specimens. It has also been prepared with the novice in mind and can be applied to both 
natural history and archaeological specimens. As most specimens worldwide seem to be dry, green, remnant or charcoal (which can be curated in essentially the same way, see below for exceptions), these guidelines are primarily directed towards their care. These guidelines can also be applied to waterlogged specimens; however, specific considerations for their care are included at the end of each section, where appropriate.

To ensure the long-term viability of dendrochronological collections, stakeholders should develop and consistently apply an appropriate set of standards of care. Any such standards should account for the necessary degree of flexibility associated with a multidisciplinary field that advances rapidly. Below is a possible baseline to which it is hoped the community will add, amend, and adjust to arrive at a suitable version that can be practically applied.

The following works can also be used as general guides for the curation of dendrochronological materials, although neither is tailored for wood: (1) for natural history collections see Rose et al. (1995a, 1995b); (2) for archaeological collections see U.S. National Park Service (2000). Topical and detailed suggestions for resolving common conservation, curation, and other collections-related issues can also be found in the U.S. National Park Service's Conserve O Gram series (http://www.nps.gov/history/museum/publications/ conserveogram/cons_toc.html).

\section{Basic Concepts}

(1) Because of the generally consistent and stable nature of wood, curation of wood specimens is not inherently complicated (Hoadly 2000; "stable" relative to the long-term curation needs for bronze artifacts, ice cores, or human tissue, for example, and without the need for security called for by gold artifacts, human remains, etc.). Some exceptions may include specimens curated for entomological study (see Raphael 1994).

(2) Two categories of material are typically found in dendrochronology: dry or air-dried specimens (i.e. charcoal, remnant wood, living-tree cores and sections, freeze-dried) and waterlogged specimens (i.e. as recovered from bogs and lakes). Significant differences may exist in proper curation, and are outlined below.

(3) Specimens should be curated in order to preserve their viability for their original research intent (i.e. as vouchers), and, as a secondary concern, to be available for new analyses.

(4) Association of metadata with individual specimens is crucial. Specimens without appropriate metadata are of limited scientific utility and typically should not be accepted for curation. Exceptions include specimens with other intrinsic, educational, or outreach value (e.g. a specimen that has only genetic identification and lacks source information may be useful for species voucher sets or educational purposes).

(5) For most tree-ring specimens, the time required for preparation, analysis and publication will necessitate that conservation-related issues are resolved prior to curation (e.g. labeling, stabilization of moisture levels, elimination of mold/pests). Conservation is a separate issue not covered in this paper.

(6) "Scientific papers and reports resulting from [dendrochronological] research should specify which institution holds the physical material." (Harris et al. 2009:154)

\section{Accessioning Specimens into Permanent Collections}

(1) Specimens received for curation should be prepared for placement into an archive with complete metadata, including any necessary conservation.

(2) Specimens should be removed immediately from any vessel that retains moisture, including aluminum foil, plastic wrap, straws, plastic containers, etc.

(3) Observe and inspect specimens for pests and fungi before placing them in the archives. Fungi are typically found on cutting surfaces and between the bark (if present) and sapwood. Wounds in the specimen, galleries, wood pulp, eggs, or excrement can indicate the presence of pests. In the event of either pests or fungi, quarantine the specimen(s).

(4) Ensure that individual specimen labels are legible. If not, immediately consult with the PI/ 
submitter and resolve any outstanding labeling issues before continuing.

(5) Avoid contaminating specimens with chemicals and be aware that the specimens may have been contaminated in the field, especially with lubricants such as oil and WD- $40^{\mathrm{TM}}$ (GrissinoMayer 2003). WD- $40^{\mathrm{TM}}$ is commonly used during specimen collection to clean field instruments, but it is not consistently recorded in field notes. Such contaminants can limit a specimen's utility for dendrochemical analyses (Grissino-Mayer 2003).

(6) Researchers should provide written documentation of all substances and methods that were used to collect and prepare the specimens, including lubricants used to clean field equipment and glue used during mounting (Ferguson 1970; Harris et al. 2009), indicating, when available, brand and batch number.

\section{Waterlogged:}

(1) Freeze-drying specimens with depleted cellulose can offer a chemical-free preservation, but alters the shape of the specimen. See Babiński (2011) for a discussion of freeze-drying and distortion. After freeze-drying, the wood can be curated similarly to air-dried specimens. To the best of the author's knowledge the long-term effects of freeze-drying dendrochronological specimens have not been studied, but some investigations for archaeological materials have been conducted (e.g. Jones et al. 2009). Note: freezedrying is often combined with the use of polyethylene glycol, which may be necessary if cellulose remains or to prevent excessive distortion (Hamilton 2000).

(2) A common method for conservation of waterlogged material, especially archaeological material, is by saturation with polyethylene glycol, or "PEG" (see Hamilton 2000; Jones 2010). PEG is typically unsuitable for preservation of dendrochronology materials as it changes the chemical composition of the wood, precluding, or at very least complicating, future use in chemical analyses. Other conservation methods, such as silicone oil (Smith 2003), have similar complications.

(3) If the specimens were not collected in situ, it is possible that biocides or insecticides were used in the water of storage or holding tanks for the material (used to keep the wood submerged during prolonged curation, excavation or analysis). Retain a complete record of these chemicals in the metadata.

\section{Air-Drying Specimens}

(1) Use fans to facilitate air-drying, especially for green specimens. Dry as slowly as possible and check progress regularly to avoid distortion. Placing heavy objects (such as sandbags) on the specimen while drying can limit distortion.

(2) The moisture content of wood should be $2-8 \%$ after it has been dried and cured. See Hoadly (2000:111-130) for further discussion of moisture content.

(3) Even with careful drying, some cracking is likely to occur. If a specimen separates into multiple pieces, assemble and label the pieces. Keep them together in a small breathable container, such as an acid-free envelope without adhesive. Do not use plastic containers.

(4) Note: cores should not be reassembled, nor should they be prepared and mounted by anyone lacking specialist training in dendrochronology. Sections can be reassembled at the discretion of the curator/caretaker.

\section{Waterlogged:}

(1) Waterlogged specimens should remain wet unless properly conserved.

(2) If specimens have dried, no attempt should be made to re-waterlog them (Hillam 1998). Store them as dried specimens and note the change in the metadata.

\section{Storage Conditions}

(1) Store specimens as air-dried, wet, or frozen, depending on how the specimens were submitted. The majority of specimens will be air-dried.

(2) Consistency in storage environment is critical (Peck 1973). Avoid fluctuations in RH of $\pm 10 \%$. Wood being hydroscopic, excess (or insufficient) moisture may distort specimens, including cracking and warping, and encourage pests and fungi. 
Consistency is especially critical for specimens employed in high resolution analysis or imaging, such as densitometry.

(3) Avoid extreme fluctuations in temperature.

(4) After specimens are air-dried, store in a low RH environment. Prominent archaeological manuals recommend $\mathrm{RH} 45-60 \%$ for wooden objects (e.g. U.S. National Park Service 2000, v. 1, 4D, 4:14; Hamilton 2000). However, for dendrochronological specimens, $\mathrm{RH}$ between $20-40 \%$ may be preferable, especially when diagnostic features such as carvings are not present.

(5) Consider storing specimens elsewhere if the above $\mathrm{RH}$ ranges cannot be maintained, especially if $\mathrm{RH}$ exceeds $60 \%$. Note that arid locations may have difficulty maintaining higher levels, whereas humid locations may have difficulty attaining sufficiently low levels (see Hoadly 2000:134 Fig. 7.2 , for approximate $\mathrm{RH}$ ranges in the continental U.S.).

(6) Specimens vary greatly in size. Store in specimen cabinets, boxes on shelves or as oversized objects on shelves, elevated at least $10 \mathrm{~cm}$ (4 in.) off the ground.

\section{Waterlogged:}

(1) Store waterlogged specimens in enclosed tanks or containers. If the storage unit cannot be sealed airtight, beware of evaporation.

(2) Check regularly and change water when necessary to avoid harboring fungal and biological growth.

\section{Charred Wood/Charcoal \& Freeze- Dried Specimens}

(1) These specimens are often very brittle and susceptible to degradation if not kept in a low RH environment (preferably 20-40\% RH).

(2) If specimens are brittle, they should be wrapped in natural cotton batting or lightly bound with natural cotton string for protection and consolidation.

(3) Do not wrap charcoal in aluminum foil, plastic, or synthetic batting. Foil and plastic wrap trap moisture and the specimen may degrade quickly. Synthetic batting catches rough edges of a specimen; its removal often results in loss of data.
(4) Note: if a specimen arrives wrapped in synthetic batting but is otherwise stable, do not remove the batting. Wait until a specimen is required for use, at which time the synthetic can be removed and replaced with natural cotton.

\section{Special Considerations for Bulk Specimens}

(1) Oversized sections or irregularly shaped large specimens can be reinforced by attaching them to an archival-quality backing board with minimal amounts of water-soluble glue. Use a baseboard up to $10 \mathrm{~mm}$ thick (3/8 in.). The baseboard should slightly exceed the circumference of the specimen (ca. 10 to $20 \mathrm{~mm}$ [1/2 to $3 / 4 \mathrm{in}$.]). Alternatively, the pieces can be labeled and placed on the base support (if not affixed, an outline of each piece should be drawn on the base with corresponding labels), or collected in a breathable, acid-free container.

(2) Do not use plywood, particleboard, or similar material for the backing board, because problems with off-gassing.

Waterlogged:

(1) A bulk specimen can be stored in a single built-to-fit container. If necessary, use an archival quality acrylic-based plastic baseboard. Note the brand and chemical composition of the plastic in the metadata.

\section{Storage Containers}

(1) Box sizes should be consistent within a storage unit to support ideal use of space and regular shelving.

(2) Store specimens in acid-free, $\mathrm{pH}$-neutral boxes made of a breathable material, such as cardboard. (3) Reinforce boxes with an acrylic adhesive tape, such as $3 \mathrm{M}^{\mathrm{TM}} 850$, which will bond to cardboard. This will ensure that the box will hold the weight of the specimens over time.

(4) Use sterile natural cotton batting to support specimens or cushion fragile specimens in a single box. (5) Multiple specimen types (remnant, charcoal and archaeological) can be stored together, but do so based on provenience. 
(6) Do not use: (a) enclosed plastic storage containers, (b) vinyl-based tapes (such as duct tape), cellulose adhesive tapes (such as "Scotch" tape), water-activated tape, reinforced gummed tape (brown packing tape), etc., as these varieties are typically acidic and not appropriate for curation and/or are not designed for long-term applications, or (c) synthetic padding with friable specimens.

\section{Waterlogged:}

(1) Store in watertight containers that permit the specimen to be completely covered by at least $5 \mathrm{~cm}$ (2 in.) of water.

(2) Include as few foreign objects as necessary to stabilize the specimen (i.e. batting).

(3) Use deionized or distilled water.

\section{Shelving and Labeling}

(1) Store large bulk specimens directly on shelves. Store bulk specimens vertically with spaces between them to permit air circulation. This reduces the likelihood of mold growth caused by trapped moisture. If wood is stacked horizontally, use spacers between the specimens to permit circulation.

(2) Cover the shelves to minimize dust collecting on specimens.

(3) Minimize handling and movement of large or friable specimens to avoid the loss of edge material, and thus valuable data.

(4) Make and attach data labels so they are easy to see in order to minimize moving specimens.

(5) Labels should be of archival quality such that they resist fading, water damage, etc.

(6) A tracking method such as radio-frequency identification could be useful for both individual specimens and/or groups based on provenience.

(7) Each specimen should have its own unique identifier and be entered into a catalog.

\section{Cleaning}

Over time terpenes and resins in the wood migrate to the surface and obscure details such as tree rings. Airborne contaminants may accumu- late on exposed surfaces. First, vacuum the specimen. Next, use denatured ethanol to remove surface contaminants. The surface can be sanded with successively finer grits of sandpaper, or prepared with a sharp blade, to remove any potential surface contaminants and to make the rings more visible.

\section{Pests and Fungi}

(1) Pests and fungi, including mold, most often occur when green wood is first brought out of the field and the specimens are wrapped in plastic film, aluminum foil, or straws used to store cores in the field. Generally, these complications should be resolved during the analysis phase long before specimens are curated.

(2) If evidence of fungi is found, vacuum the affected surface(s) with a HEPA-filtered vacuum; otherwise mold may move further into the substrate. Dry affected specimens in a drying oven. The oven should be used only to quiesce certain fungi and to kill insects.

(3) Clean the affected surface(s) with denatured ethanol (usually $90 \%$ ethanol and $10 \%$ methanol) or a dilute bleach solution made from $150 \mathrm{ml}(2 / 3$ of a cup) of bleach to 3.75 liters (1 gallon) of water. With a spray bottle dampen or wet the surface, but do not saturate the wood. Brush off the contaminated wood with a stiff nylon brush (do not use a stiff brush on charred, charcoal or waterlogged specimens). It is also possible to scrape off fungi with a paint scraper or similar tool. Lightly mist the surface again and let it airdry.

(4) Do not use isopropanol for cleaning wood specimens, as it can complicate later chemical analysis.

\section{CONCLUSIONS}

Responsible research conduct at all levels and in all fields of science using specimens should include preservation and proper organization of specimens so they are readily available for new analyses, confirmation, or reinterpretation of results. Eckstein and Cherubini (in press, p. 1) 
state that there are "...minimum requirements for a discipline to be accepted as a science", and it seems reasonable to include proper specimen care. Indeed, there are numerous opportunities during a career to secure the future of an investigator's specimens. Be it in the public or private sphere, each grant proposal and contract negotiation is an opportunity to request funds or other support for proper care. The longer caretakers wait to implement better standards, the greater curation backlogs and problems will become. The issue at hand is how to progress. It is hoped that this paper can be used to further advance the case for curation of dendrochronological specimens.

\section{ACKNOWLEDGMENTS}

The author wishes to acknowledge the following people for their contributions to and reflections on this work: Rex Adams, Joan Bacharach, Chris Baisan, Bryant Bannister, Gretel Boswijk, Peter Brown, Jeff Dean, Catherine Hawks, Malcolm Hughes, Steve Leavitt, Greg McDonald, Daniel Nievergelt, Jim Speer, Elaine Sutherland, Tom Swetnam, Jacques Tardif, Willy Tegel, Valérie Trouet, and two anonymous reviewers. Esther Jansma's thorough review was greatly appreciated and aided in broadening the scope of material presented above. Of course, any errors and opinions are solely the responsibility of the author, and do not necessarily reflect the thoughts or policies of any institutions with which the author is or has been affiliated.

\section{REFERENCES CITED}

Arnott, H. J., 2008. Wood-The final frontier. Texas Journal of Microscopy 38(2):19-43.

Babiński, L., 2011. Investigations on pre-treatment prior to freeze-drying of archaeological pine wood with abnormal shrinkage anisotropy. Journal of Archaeological Science 38(7):1709-1715.

Baillie, M. G. L., 1982. Tree-Ring Dating and Archaeology. The University of Chicago Press, Chicago.

Baillie, M. G. L., 2002. Future of dendrochronology with respect to archaeology. Dendrochronologia 20(1/2):69-85.

Bannister, B., 1963. Dendrochronology. In Science in Archaeology, edited by D. Brothwell, and E. Higgs, pp. 161-176. Thames and Hudson, New York.
Brewer, P. W., K. Sturgeon, L. Madir, and S. W. Manning, 2010. A new approach to dendrochronological data management. Dendrochronologia 28(2):131-134.

Childs, S. T., and K. Kinsey, 2003. Costs of Curating Archeological Collections: A Study of Repository Fees in 2002 and 1997/98. Archeology and Ethnography Program, National Park Service, Washington, D.C. [Available online at http://www.cr.nps.gov/archeology/tools/feesstud.htm]

Childs, S. T., 2004. Our Collective Responsibility: The Ethics and Practice of Archaeological Collections Stewardship. Society for American Archaeology, Washington, D.C.

Cook, E. R., C. A. Woodhouse, C. M. Eakin, D. Meko, and D. W. Stahle, 2004. Long-term aridity changes in the western United States. Science 306:1015-1018.

Creasman, P. P., 2010. Extracting Cultural Information from Ship Timber. Ph.D. dissertation (Nautical Archaeology Program), Texas A\&M University, College Station, TX.

Čufar, K., 2007. Dendrochronology and past human activityA review of advances since 2000. Tree-Ring Research 63(1): $47-60$.

Dean, J. S., D. Meko, and T. W. Swetnam, Editors, 1996. Tree Rings, Environment and Humanity: Proceedings of the International Conference, Tucson, Arizona 17-21 May 1994. Radiocarbon, Tucson.

Dean, J. S., 2006. In Memoriam: Robert E. Bell 1914-2006. Tree-Ring Research 62(1):33-34.

Dean, J. S., 2009. One hundred years of dendroarchaeology: Dating, human behavior, and past climate. In Tree-rings, Kings, and Old World Archaeology and Environment: Papers Presented in Honor of Peter Ian Kuniholm, edited by S. Manning, and M. J. Bruce, pp. 25-32. Oxbow Books, Oxford.

Eckstein, D., and P. Cherubini, 2011. The "dendrochronological community" at Rovaniemi, Finland, 2010: Lessons learned from the past and perspectives for the future. Dendrochronologia in press. (doi:10.1016/j.dendro.2011.02.001).

Eckstein, D., and F. Schweingruber, 2009. Dendrochronologia -A mirror for 25 years of tree-ring research and a sensor for promising topics. Dendrochronologia 27(1):7-13.

Ferguson, C. W., 1970. Concepts and techniques of dendrochronology. In Scientific Method in Medieval Archaeology, edited by R. Berger, pp. 183-200. University of California Press, Berkeley.

Flattau, P. E., M. Boeckmann, P. Lagasse, N. Mitchell, and D. Singpurwalla, 2008. The NSF Survey of Object-Based Scientific Collections: 2008. Science \& Technology Policy Institute, IDA Document D-3707, Washington D.C. [Available online at http://www.nsf.gov/bio/pubs/reports/prelim findings_sc_2008.pdf]

Friedrich, M., S. Remmele, B. Kromer, J. Hofmann, M. Spurk, K. F. Kaiser, C. Orcel, and M. Küppers, 2004. The 12,460year Hohenheim oak and pine tree-ring chronology from central Europe - a unique annual record for radiocarbon calibration and paleoenvironment reconstructions. Radiocarbon 46(3):1111-1122.

Glock, W. S., 1934. Report on the first tree-ring conference. Tree-Ring Bulletin 1(1):4-6. 
Grissino-Mayer, H. D., 2003. A manual and tutorial for the proper use of an increment borer. Tree-Ring Research 59: 63-79.

Hamilton, D. L., 2000. Wood conservation. In Methods of Conserving Archaeological Materials from Underwater Sites, http://nautarch.tamu.edu/crl/conservationmanual/File6.htm. Conservation Files: ANTH 605, Conservation of Cultural Resources I. Nautical Archaeology Program, Texas A\&M University, College Station. [Available online at http:// nautarch.tamu.edu/class/ANTH605].

Harris, S., K. Allen, P. Baker, T. Bird, D. Bowman, A. Connolly, L. d'Arville, C. Harwood, A. Rozefelds, and T. Wardlaw, 2009. Guidelines for collecting and conserving dendrochronology samples from Tasmanian public reserves. Tasforests 18:145-157.

Hawley, F. M., 1941. Tree-Ring Analysis and Dating in the Mississippi Drainage. University of Chicago Press, Chicago.

Hillam, J., 1998. Dendrochronology: Guidelines on Producing and Interpreting Dendrochronological Dates. English Heritage, London.

Hoadley, R. B., 2000. Understanding Wood: A Craftsman's Guide to Wood Technology. The Taunton Press, Newton, CT.

Jansma, E., 2006. NOaA 3 Dendrochronologie. Dutch National Research Agenda for Archaeology. [Available online at: http:// noaa.nl/toc/balk1-4-3.htm].

Jansma, E., P. W. Brewer, and I. Zandhuis, 2010. TRiDaS 1.1: The tree-ring data standard. Dendrochronologia 28(2):99 130.

Jones, D. M., Editor, 2010. Waterlogged Wood: Guidelines on the Recording, Sampling, Conservation and Curation of Waterlogged Wood. English Heritage Publishing, Belgium.

Jones, S. P. P., N. Slater, M. Jones, K. Ward, and A. Smith, 2009. Investigating the processes necessary for satisfactory freeze-drying of waterlogged archaeological wood. Journal of Archaeological Science 39:2177-2183.

Kuniholm, P. I., 2001. Dendrochronology and other applications of tree-ring studies in archaeology. In Handbook of Archaeological Sciences, edited by D. R. Brothwell, and A. M. Pollard, pp. 36-46. John Wiley \& Sons, Ltd., London.

Kuniholm, P. I., 2002. Archaeological dendrochronology. Dendrochronologia 20(1/2):63-68.

Laxton, R. R., C. D. Litton, and R. E. Howard, 2001. Timber: Dendrochronology of Roof Timbers at Lincoln Cathedral. James and James Ltd., London.

Lyons, P. D., and A. W. Vokes, 2010. The role of fee structures in repository sustainability. Heritage Management 3(2): 213-232.

Mares, M. A., 2009. Natural science collections: America's irreplaceable resource. BioScience 59(7):544-545.

McParland, L. C., M. Collinson, A. C. Scott, and G. Campbell, 2009. The use of reflectance values for the interpretation of natural and anthropogenic charcoal assemblages. Archaeological and Anthropological Sciences 1(4):249-261.

Nash, S., 2000. Seven decades of archaeological tree-ring dating. In It's About Time: A History of Archaeological Dating in North America, edited by S. Nash, pp. 60-83. The University of Utah Press, Salt Lake City.
Nash, S., 1999. Time, Trees, and Prehistory: Tree-Ring Dating and the Development of North American Archaeology, 1914 to 1950. University of Utah Press, Salt Lake City.

Peck, E. C., 1973 (revised). Moisture content of wood in use. Forest Service Research Note: FPL-0226. U.S. Department of Agriculture.

Raphael, T., 1994. An insect pest control procedure: the freeing process. Conserve O Gram 3(6):1-4. National Park Service, Washington, D.C.

Robinson, W. J., E. Cook, J. R. Pilcher, D. Eckstein, L. Kairiuskstis, S. Shiyatov, and D. A. Norton, 1992. Some historical background in dendrochronology. In Methods of Dendrochronology: Applications in the Environmental Sciences, edited by E. Cook, and L. A. Kairiukstis, pp. 1-22. Kluwer Academic Publishers, Dordrecht.

Rose, C. L., C. A. Hawks, and H. H. Genoways, Editors, 1995a. Storage of Natural History Collections: A Preventative Conservation Approach. Society for the Preservation of Natural History Collections, Washington, D.C.

Rose, C. L., and A. de Torres, Editors, 1995b. Storage of Natural History Collections: Ideas and Practical Solutions. Society for the Preservation of Natural History Collections, Washington, D.C.

Santiago-Blay, J. A., J. B. Lambert, and P. P. Creasman, 2011. Scientific Advisory - Expanded Applications of Dendrochronology Collections: Collect and Save Exudates. Tree-Ring Research 67(1):67-68.

Schulze, B., C. Wirth, P. Linke, W. A. Brand, I. Kuhlman, V. Horna, and E. D. Schulze, 2004. Laser ablation-combustionGC-IRMS: a new method for online analysis of intra-annual variation of $\delta^{13} \mathrm{C}$ in tree rings. Tree Physiology 24(11): 1193-1201.

Skog, J., R. M. McCourt, and J. Corman, 2009. The NSF Scientific Collections Survey: A Brief Overview of Findings. National Science Foundation, Washington D.C. [Available online at http://www.nsf.gov/pubs/2009/nsf09044/nsf09044. pdf]

Smith, C. W., 2003. Archaeological Conservation Using Polymers. Texas A\&M University Press, College Station.

Solomina, O., and P. Cherubini, 2002. "Tree rings and people", an international conference on the future of dendrochronology: an overview. Dendrochronologia 20(1/2):13-19.

Stankowski, C., 2009. Collection Preparation Guidelines: February 2009. San Diego Archaeological Center, San Diego. [Available online at http://www.sandiegoarchaeology.org/ PDF/Collection\%20Preparation\%20Guidelines\%202009.pdf]

Stokes, M. A., and T. L. Smiley, 1968. An Introduction to TreeRing Dating. University of Arizona Press, Tucson. (Reprinted 1996).

U.S. National Academy of Sciences, National Academy of Engineering, and the Institute of Medicine, 2009. On Being a Scientist: A Guide to Responsible Conduct in Research (Third Edition). The National Academies Press, Washington, D.C.

U.S. National Park Service, 2000. The Museum Handbook. National Park Service Museum Management Program, Washington, D.C. [Available online at http://www.nps.gov/ museum/publications/handbook.html] 
U.S. National Science and Technology Council, Committee on Science, Interagency Working Group on Scientific Collections, 2009. Scientific Collections: Mission-Critical Infrastructure of Federal Science Agencies. Office of Science and Technology Policy, Washington, D.C. [Available online at http://
www.whitehouse.gov/files/documents/ostp/NSTC\%20Reports/ Revision_1-22_09_CL.pdf]

Received 17 February 2011; accepted 14 April 2011. 